\title{
Linguagens da comunicação e desafios educacionais: o problema da formação dos jovens docentes
}

\section{Adilson Citelli}

Professor titular junto ao Departamento de Comunicações e Artes da ECA/USP, onde ministra cursos de graduação e pós-graduação. Orienta dissertações e teses nas áreas de Comunicação e Linguagem, com ênfase nas subáreas comunicacão/educacão, comunicação/linguagem. É coeditor da revista Comunicação \& Educação, bem como pesquisador $1 C$ do CNPQ. E-mail: citelli@uol.com.br

Resumo: $\mathrm{O}$ artigo sistematiza alguns dados de pesquisa que estamos realizando na interface comunicação/educação. O objetivo é verificar como os jovens professores do Ensino Fundamental e Médio, com faixa etária de até 30 anos, vivenciam e trabaIham com as culturas mediáticas.

Palavras-chaves: comunicação, educação, escola, jovens professores, cultura mediática.
Abstract: This text systematizes data collected in the research that discusses the interface between communication and education. The main objective is to verify how young teachers from fundamental and medium school systems, in the age group up to 30 years old, are living and working with new media cultures

Keywords: Communication, education, school, young teachers.

Este artigo resulta de alguns dos dados que acompanham pesquisa maior, realizada entre 2006 e 2008, orientada para verificar como os jovens docentes da rede pública estadual e municipal de São Paulo, com idade até trinta anos, quando da aplicação dos questionários e realização das entrevistas, se inserem no interior das relações comunicativas. Dela fez parte um grupo de setenta e nove professores ${ }^{1}$.

Estabelecemos duas estratégias para recolher e organizar os dados obtidos junto aos professores que compuseram a amostra. De início aplicaram-se questionários com enunciados abertos e fechados. Tal tipo de encaminhamento teve o propósito de recolher informações e mesmo manifestações livres, atinentes a itens que incluíam contornos profissionais, hábitos de frequência aos meios de comunicação, expectativas com relação à carreira etc.

Recebido: 22.11.2009

Aprovado: 07.12.2009

1. A íntegra dos dados consta de relatório enviado ao CNPq no início de 2009. Material de posse do autor. 
Tal procedimento se fez acompanhar de contatos presenciais com grupos de professores e discussões capazes de melhor esclarecer o nosso problema principal: as relações comunicação/educação.

Os questionários foram aplicados junto a professores do Ensino Básico, abrangendo desde a educação infantil, passando pelo Fundamental I e II, até o Médio. A enquete ocorreu ou nas próprias escolas ou em encontros e reuniões de professores promovidos pelas Secretarias de Educação e mesmo em cursos de formação continuada. E se buscou garantir o critério de representação pelas regiões norte, sul, leste, oeste e centro. Duas cidades da grande São Paulo tiveram escolas incluídas: Guarulhos e São Bernardo do Campo.

A diversidade da amostra, no que tange à abrangência dos níveis de ensino antes indicados, foi perseguida em decorrência dos vetores postos no horizonte maior de interesse da pesquisa. Ou seja, o nosso problema não é o de segmentar grupos de docentes, a não ser quanto à faixa etária, mas perseguir temas como os da formação inicial e das relações com os desafios suscitados pelas linguagens e suportes da comunicação, quer no que diz respeito à recepção, quer no uso dos meios junto aos ambientes educativos.

Buscaremos, nos limites impostos por este artigo, esclarecer um pouco melhor o andamento da investigação, no que ela facultou referência a alguns dados, comentários e generalizações teóricas.

\section{A QUESTÃO DA FAIXA ETÁRIA}

Duas razões principais levaram a que segmentássemos a amostra, reunindo-a em torno dos professores da referida faixa etária.

Em primeiro lugar, por fixarmos a hipótese de que os jovens docentes cumpriram a sua formação escolar e profissional em cenário marcado por ampla e profunda mudança nos padrões tecnológicos, nos circuitos comunicacionais e da própria sociabilidade. Daí poderia decorrer condição favorável para o surgimento de uma nova geração de educadores voltada a trabalhar sem grandes intercorrências com os desafios propostos pela comunicação ao sistema educativo.

Observando-se o quadro etário que fez parte da pesquisa, encontrar-se-ão professores nascidos em 1975, com maior concentração em 1976, até 1986. Vale dizer, e apenas como momentâneo exercício de aproximação, tomando-se os mais velhos da amostra, e considerando a idade de sete anos como de ingresso

2. Dois docentes completaram 31 anos no desenrolar da pesquisa. Tinham 30 anos quando o trabalho de coleta e acompanhamento do grupo começou. Por não significar desvio capaz de comprometer a estrutura dos dados, os professores foram mantidos no conjunto da amostra. no nível Fundamental I, teríamos que a conclusão deste ciclo se deu em 1990, do Médio em 1993 e do Superior, em 1997 (tabelas 1 e 2).

No interior deste grupo etário ${ }^{2}$, o tempo efetivo de exercício do magistério varia em anos, sendo que a maior porcentagem (19.94\%, excluídas as sete abstenções) apresenta adensamento no período de cinco anos (tabela 3).

Ou seja, retirados os casos em que o docente ainda está cursando o $3^{\circ}$ grau, a vivência escolar da maior parte do grupo ocorreu junto com o crescimento, no Brasil, dos sistemas e processos comunicacionais, acentuadamente a partir 

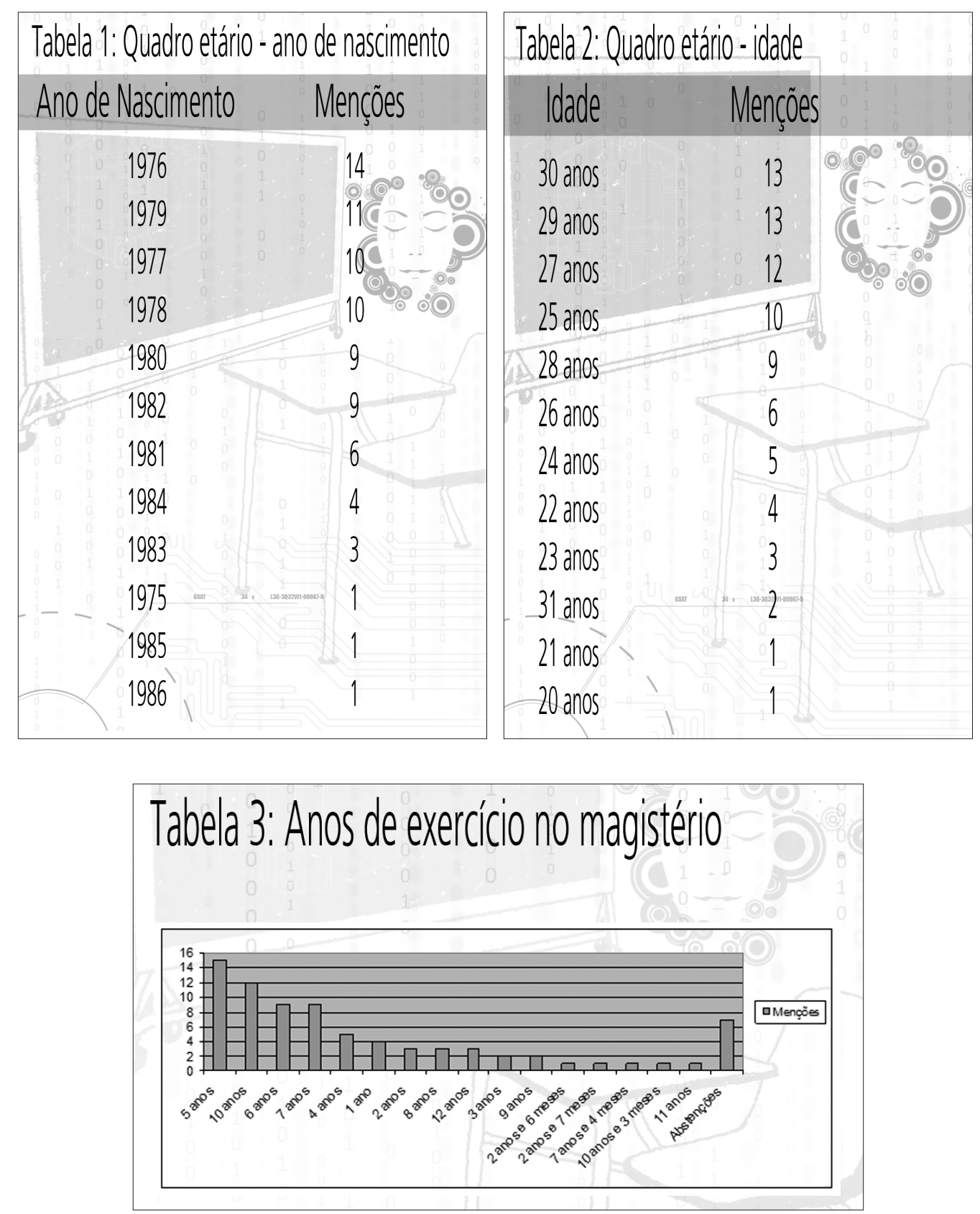

dos anos 1990, quando acontece a primeira grande expansão dos computadores pessoais e do acesso à internet. Se atentarmos para o tempo de magistério, verificaremos estar diante de um grupo, percentualmente significativo, que inicia o exercício profissional já nos anos 2000. Observando a questão por este ângulo, ficamos diante de um conjunto de referências que posicionam tanto os jovens docentes como os seus atuais alunos dentro de um universo relativamente próximo ao convívio com as novas tecnologias e suas linguagens.

Esperava-se, pois, a existência de práticas didáticas e pedagógicas voltadas aos diálogos sistemáticos entre estratégias tradicionais da escola - o termo tradi- 
cional não carrega, aqui, qualquer conotação pejorativa ou de oposição valorativa a uma possível (pós)modernidade - e propostas de inovação equacionadas, sobretudo, a sociabilidades constituídas contemporaneamente e que recortam a vida de discentes e docentes, malgrado as nuances culturais, socioeconômicas, etárias etc., que os singularizam.

Em segundo lugar, desejávamos contrapor dados que obtivemos com pesquisas mais amplas, desenvolvidas entre 2000 e 2004, com o intuito de verificar se é possível estabelecer padrões de divergência e convergência no interior da sala de aula e mesmo de comportamentos dos docentes diante dos media, em decorrência de processos formativos procedidos em temporalidades diferentes: as dos docentes que passaram pela escola antes e depois da década de 1990.

Assim, o propósito de focalizar a pesquisa em uma faixa etária de professores resultou do interesse em saber até onde as dinâmicas comunicacionais poderiam infletir, refletir, completar, sugerir, afastar, problematizar, as atividades destes profissionais em sala de aula, assim como ajudar a esclarecer um pouco mais acerca dos próprios hábitos mediáticos levados a termo pelos docentes.

\section{AS RELAÇÕES MEDIÁTICAS}

A preocupação em identificar como determinado segmento docente convive com os meios de comunicação fez com que se elaborassem perguntas sobre frequência à televisão e ao rádio; leitura de jornais e revistas; acesso à internet. Enfim, houve o intuito de saber como o docente age como destinatário, ou mesmo enquanto elaborador de produtos afeitos aos media, a despeito de voltados à destinação didática: caso de filmes, vídeos, programas de rádio etc. Afinal, este é um dos contextos nos quais são elaborados não apenas perfis profissionais, mas também formas de vida, interesses particulares, fontes de informações, redes de sociabilidades etc. Ou seja, ao mesmo tempo estamos diante do professor cidadão e do cidadão professor.

Verifique-se, a título de exemplo, o aumento no número de docentes que passaram a ter computadores em suas casas:

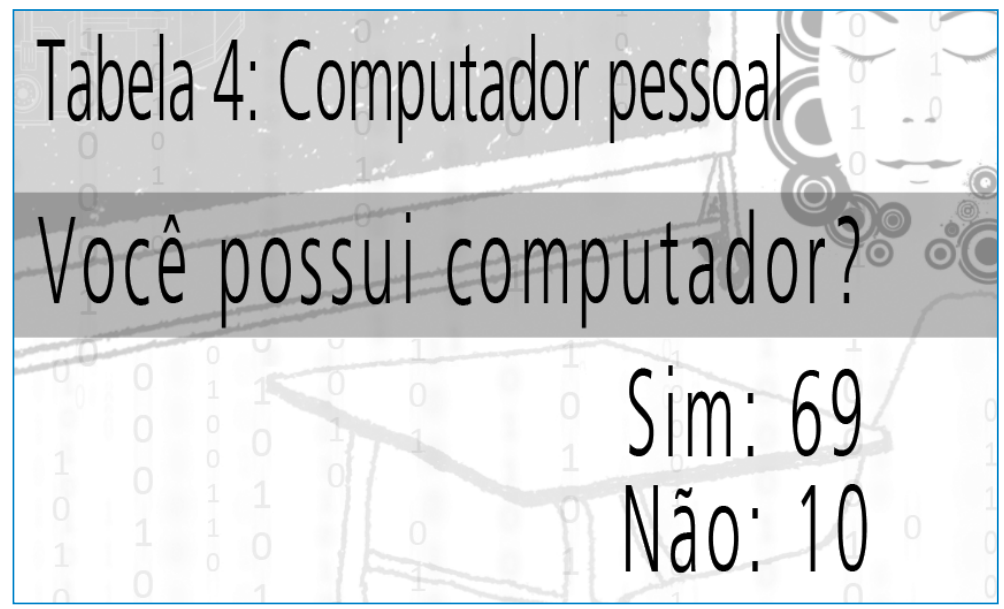


O fato de $87 \%$ responder positivamente é fenômeno recente, dado que, em pesquisa que realizamos em 2004, os números estavam em torno de $40 \%$.

Ou em outra pergunta visando saber se, mesmo não tendo posse doméstica do equipamento, os professores dele fazem uso, as respostas, neste caso, atingiram a totalidade da amostra. E para se ter elemento comparativo, veja-se a tabela a seguir.

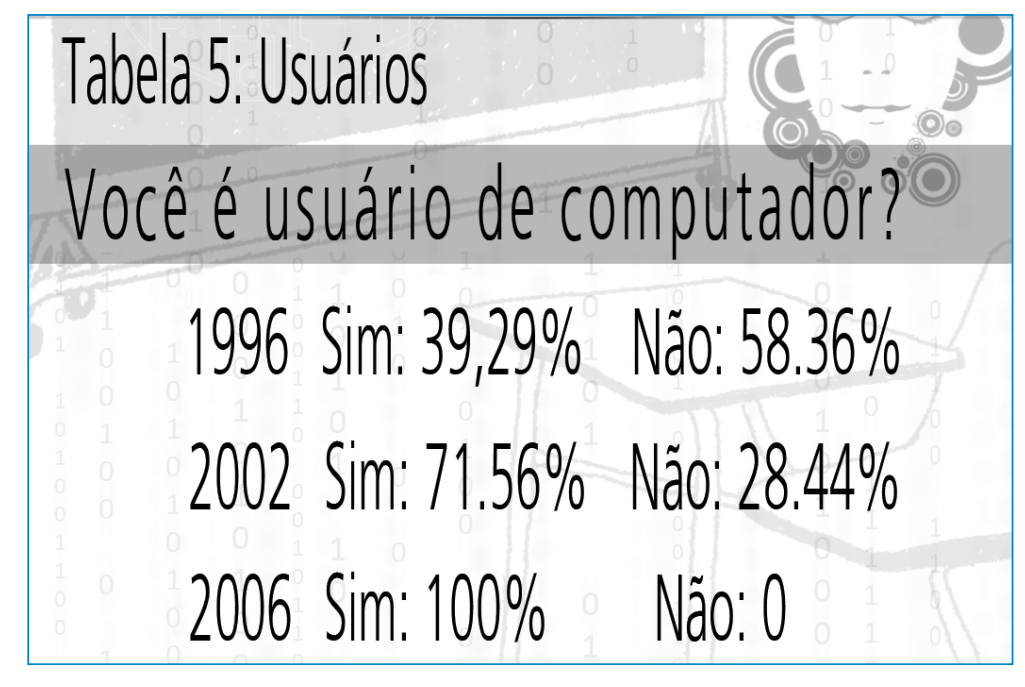

Como se reconhece, a formação inicial dos professores objeto da pesquisa ocorreu no interior de um processo de comunicação generalizada ${ }^{3}$, ou, nos termos de Antônio Fausto Neto, de mediatização social ${ }^{4}$. Nesta mesma área semântica ocupada em designar a capilaridade social dos meios de comunicação, insere-se a referida expressão de Eliseo Verón: hipermediatização da sociedade. O conceito de midiatização generalizada foi utilizado, também, por Muniz Sodré:

Por midiatização entenda-se, assim, não a veiculação de acontecimentos por meios de comunicação (como se primeiro se desse o fato social temporalizado e depois o midiático, transtemporal, de algum modo), e sim o funcionamento articulado das tradicionais instituições sociais com a mídia. A midiatização não nos diz o que é a comunicação e, no entanto, ela é o objeto por excelência de um pensamento da comunicação social na contemporaneidade, precisamente por sustentar a hipótese de uma mutação sociocultural centrada no funcionamento atual da comunicação ${ }^{5}$.

Vale dizer, detivemo-nos sobre uma geração cuja história de vida corre junto com a constituição da esfera pública segundo os ditames decisivos dos media. O termo öffentlichkeit (esfera pública), formulado por Emanuel Kant, operado, em seguida por Hannah Arendt, Jürgen Habermas, entre outros, foi desdobrado em expressões como espaço público e mesmo vida, interesse, lugar público. Observe-se que o enunciado kantiano não possui dimensão concreta, de um lugar delimitado espacialmente, mas indica que, independentemente das circunscrições físicas, é possível produzir informações, ideias, conceitos que atuam junto aos cidadãos.
3. Ver, GIANNI, Vattimo. A sociedade transparente. Lisboa: Relógio D’Água, 1989.

4. Expressão utilizada em mesa-redonda na Escola Superior de Propaganda e Marketing de São Paulo, em 2004.

5. SODRÉ, Muniz. Revista Matrizes, São Paulo: ECA/USP, n. 1, p. 17, 2007. 


\section{comunicação \& educação • Ano XV • Número 1 • jan/abr 2010}

O percurso acadêmico dos jovens professores acontece, portanto, fundindo dimensões formais, informais e não formais, num cruzamento em que instituição escolar e circuitos comunicacionais disputam lugares simbólicos, informações e, guardadas as distâncias e propriedades de cada uma daquelas instâncias, conhecimentos. Trata-se de um contexto singular que força a intensificação dos diálogos entre o dentro e o fora da sala de aula, requisitando dos ambientes educadores formais um novo tipo de tratamento, andamento e, sobretudo, estratégias didáticas e pedagógicas que não retirem dos seus horizontes de preocupações o fato de existirem outras dinâmicas a concertarem os processos de ensino-aprendizagem. Neste quadro, está pressuposto que o jovem docente tenha cumprido o seu circuito escolar ativando um nível de relação com os media, ao mesmo tempo contínuo, pois referido ao dia a dia de cada um dos futuros professores, e integrado a um cenário tecnológico, operacional, que funciona como presença permanente: computador, rádio, televisão, DVD etc.

A questão evidenciada neste momento é a seguinte: o fato de existirem novas sociabilidades, vínculos naturalizados entre o sujeito e os múltiplos suportes técnicos, teria alcançado o percurso profissional do futuro docente, ele próprio formador de outros tantos jovens, ainda mais afeitos ao circuito da comunicação generalizada? Na eventualidade de os jovens docentes haverem recebido formação adequada para trabalhar neste cenário de mediatização social, estariam eles retraduzindo em sala de aula os fluxos, processos, naturezas, formulados pelas culturas mediáticas, segundo uma perspectiva educacional e pedagogicamente equacionada aos ditames da escola, dos propósitos que devem reger a construção de uma cidadania transformadora, crítica e competente para enfrentar os desafios que esperam os discentes? É interessante observar o livro de Marc Prensky, Don't bother me, mom. I'm learning! ${ }^{6}$, que formula a ideia da existência de migrantes digitais e nativos digitais. Os primeiros marcados por uma cultura analógica, cujo aparelho perceptual e cognitivo trabalha, ainda, à base dos mecanismos lineares; os segundos formam os segmentos mais jovens, cuja forma mentis opera em ritmo rápido, com procedimentos mais próximos do aleatório (rondômico), fundados nas linguagens digitais. Falamos, aqui, de uma geração de docentes que está na passagem entre os migrantes e os nativos.

6. PRENSKY, Marc. Don't bother me, mom. I'm learning! [Não me aborreça, mãe. Estou estudando]. St. Paul, Minnesota: Paragon House, 2006.

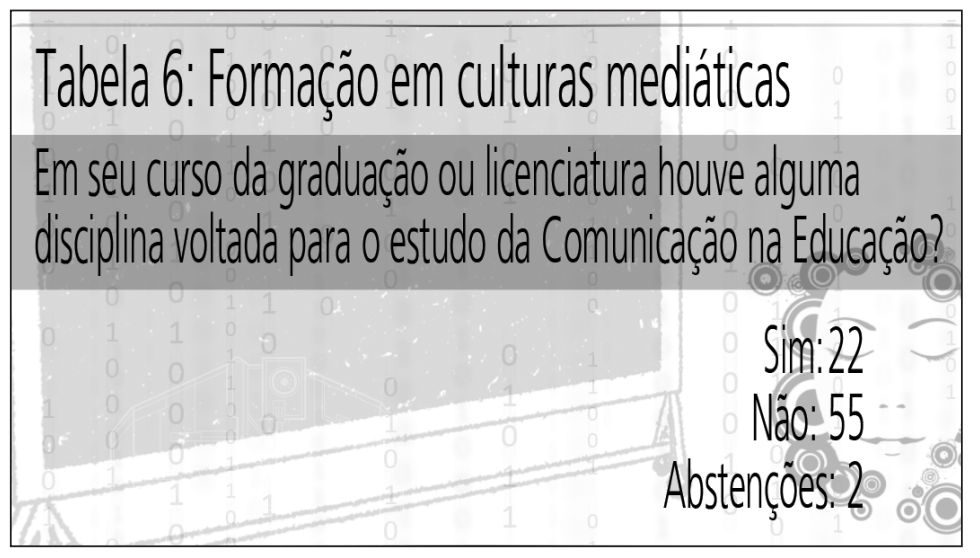


Da pesquisa depreende-se que os jovens docentes revelam insegurança para atuar com as culturas mediáticas e as linguagens que as ensejam.

É preciso lembrar que mesmo os $27.84 \%$ que responderam afirmativamente, ao nomearem as disciplinas ou disseram não se lembrar ou incluíram improcedências como Comunicação e Expressão (a rigor Língua Portuguesa), Linguística, Didática etc.

Instados a responder sobre o conteúdo aprendido nas disciplinas que, teoricamente, estariam dedicadas aos problemas confluentes ao campo da comunicação, $76 \%$ se abstiveram e os demais arrolaram unidades díspares:

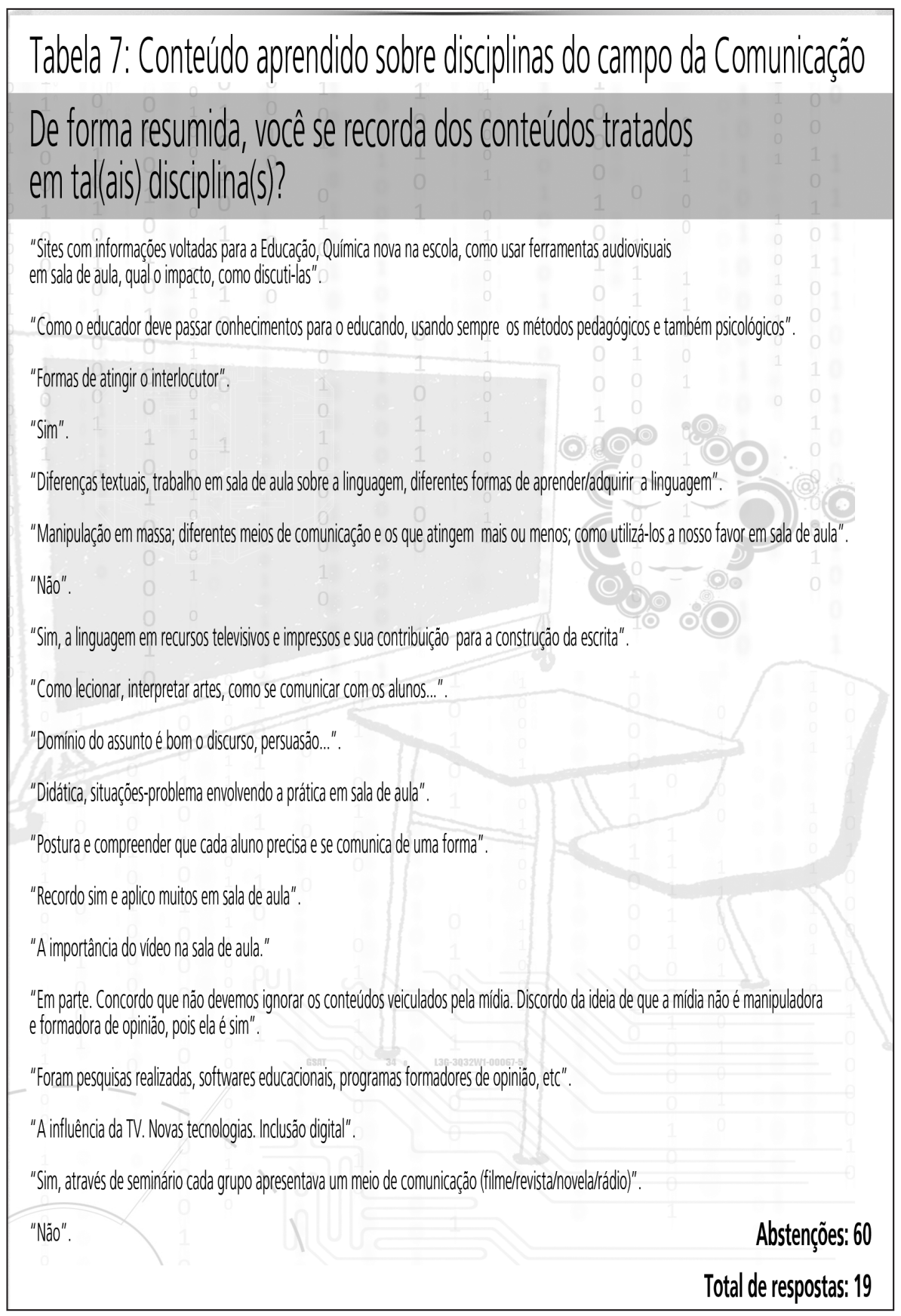




$$
\text { comunicação \& educação • Ano XV • Número } 1 \text { • jan/abr } 2010
$$

Torna-se compreensível a tabela a seguir:

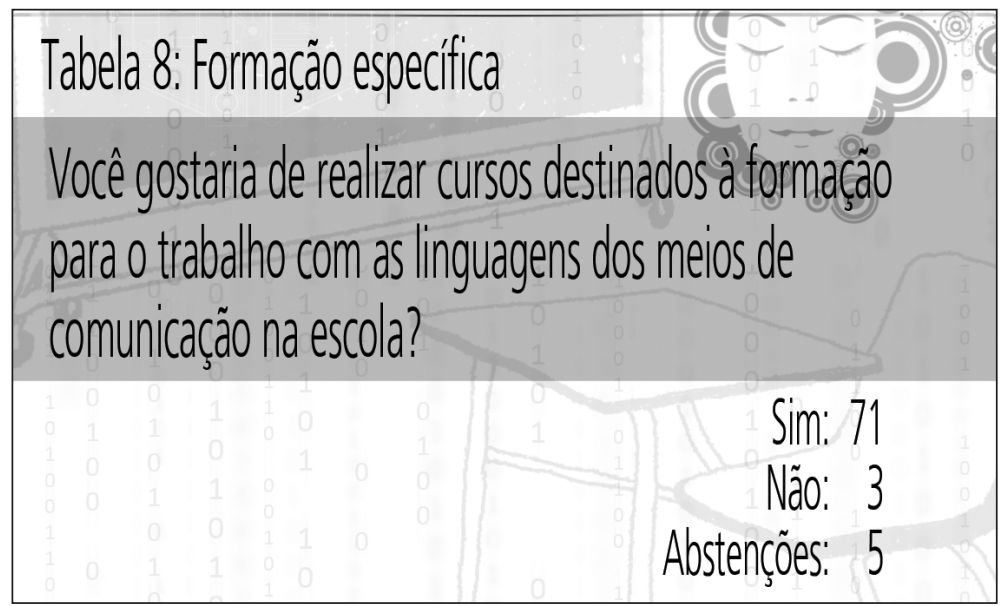

Vale dizer, quase $90 \%$ da amostra deseja realizar programas de formação continuada com vistas a suprir carências legadas durante os cursos de graduação e licenciatura. Trata-se de ampla manifestação de insegurança e/ou déficit de formação inicial para estabelecer fluxos e diálogos entre as subculturas escolares e as dos meios de comunicação.

\section{CONCLUSÕES}

A leitura do conjunto de tabelas e comentários que as ensejam permite acompanhar a existência de um grupo de jovens docentes ao mesmo tempo marcado por traços diferenciais e recorrentes quando comparados com gerações anteriores de professores alcançados pelas pesquisas que vimos realizando há alguns anos.

Os elementos diferenciais estão, sobretudo, na posse, operação e convívio junto aos veículos de comunicação, particularmente aqueles vinculados aos sistemas informacionais, telemáticos. Há um número significativamente maior de educadores formais que possuem, em suas casas, uma série de dispositivos como computador, DVD, televisão a cabo etc.; acesso à internet e a produtos imagéticos e informativos ampliados; familiaridade com os circuitos da comunicação, em seu conjunto de meios e diversidade de proposições, segundo variáveis de formas e linguagens. Ou seja, é procedente afirmar que, na generalidade de bens, produtos e serviços dados pelos e através dos media, os jovens professores fazem parte daquilo que Jesús Martín Barbero chamou de ecossistema comunicativo. Trata-se de uma geração cuja atividade pessoal e profissional acontece segundo parâmetros dados pelo polo informático-mediático ${ }^{7}$, no interior, portanto, de

7. O conceito é de LÉVY Pierre. As tecnologias da inteligência: o futuro do pensamento na era da informática. Rio de Janeiro: 34, 1993. outra etapa do desenvolvimento das comunicações e que motivaria a existência de singularidades, quando se compara a situação dos docentes mais velhos, formados há décadas, herdeiros, para se usar uma quase licença metafórica, da revolução industrial. 
Evidencia-se, portanto, circunstância em que os contextos técnicos e tecnológicos têm (sempre atentando para a amplitude da assertiva) desdobramentos distintos segundo níveis etários diferentes. E nem poderia ser de outro modo, pois os processos técnicos não se fazem à revelia de uma série de ajustes, entre eles os afeitos a marcadores etários. Reiteramos que se não se trata de promover independência de valores por redução de idade (operação simplificadora sem qualquer sustentação no terreno da cultura e das relações sociais), mas atribuir a ela, em virtude dos desdobramentos e arranjos requisitados pela ambiência tecnológica, um peso específico, uma mediação que melhor ajuda no entendimento dos marcadores profissionais dos docentes, da organização do presente universo da escolaridade formal.

Pesados os argumentos diferenciadores, é necessário agregar que a nossa pesquisa aponta, também, para recorrências entre docentes com maior ou menor tempo de exercício profissional. Como se apresenta no conjunto de dados coletados, as práticas em sala de aula não parecem ter mudado substancialmente pelo fato de os jovens docentes estarem mais integrados aos circuitos da comunicação. A posse de computadores e televisão a cabo ou o acesso à internet não garantem, nas práticas do magistério, a passagem da sociedade industrial para o polo informático-mediático. Neste aspecto, professores de diferentes faixas etárias dão continuidade a uma estrutura escolar complexa, cifrada por inúmeros problemas, que convidam à manutenção de dinâmicas propedêuticas e rotinas normatizadas que funcionam como fatores de conservação dos processos educativos formais. Existe, aqui, uma espécie de patamar comum a unir gerações diferentes de docentes.

O fato de o nosso tempo estar balizado pelos imperativos comunicacionais que se desdobram em variáveis tecnológicas, culturais, societárias, ainda não alcançou, substancialmente, a educação formal. Em nenhum dos seus níveis, pois, como verificado na pesquisa, a formação inicial dos docentes, processada, em boa parte dos casos, em instituições superiores de qualidade duvidosa, traz as marcas da precariedade. A maioria dos respondentes declara não haver frequentado, em seu percurso curricular de graduação, disciplinas que os possibilitassem entender os processos comunicacionais, e, do mesmo modo, reclama não ter acesso a cursos de formação continuada que supram tal deficiência. Daí as inevitáveis indagações: como levar para o exercício profissional conceitos, estratégias e práticas de reconhecida importância (às quais os entrevistados não estão discursivamente alheios) e que sejam capazes de aproximar comunicação e educação, sem que para tanto tenha ocorrido a devida formação profissional; como traduzir os contornos de novos configuradores culturais em contextos de pouca mobilidade e afeitos a parâmetros tradicionais; como envidar esforços para implementar mudanças à falta de estímulo e projetos consistentes que refaçam determinados caminhos hoje percorridos pelas escolas.

Estas perguntas trabalhadas ao longo de nossas pesquisas encontram o conceito de campo social mediático, como cenário dentro do qual a reflexão acerca da atividade profissional dos jovens docentes deve ocorrer. Trata-se de 
8. A palavra jogo aparece, aqui, como apropriação do conceito de jogo de linguagem, conforme formulado por Wittgenstein.

9. AUGÊ, MARC. Não lugares: introdução a uma antropologia da modernidade. Lisboa: Bertrand Editora, 1994.

10. BAKHTIN, Mikhail M.; VOLOSHINOV, Valentin N Marxismo e filosofia da linguagem: problemas fundamentais do método sociológico nas ciências da linguagem. São Paulo: Hucitec, 1989. uma ambiência multirrelacional, interdiscursiva, na qual se encontram sujeitos, espaços, tecnologias, para ficarmos nos referenciais mais evidentes. Posto de outro modo, não se trata de atribuir aos dispositivos comunicacionais uma unidirecional capacidade de forjar comportamentos, dirigir atenções, restringir ou ampliar estratégias de convencimento e manipulação, mas entendê-los como parte - nalguns momentos com força para tanger os espíritos, mas também para sofrer a perseguição dos fantasmas que não encontraram os seus corpos - de um jogo complexo ${ }^{8}$ formado por linguagens e sublinguagens e que não se reduz ou restringe aos lineamentos tecnológicos.

O campo social mediático como lugar - ou não lugar, se quisermos acompanhar a discussão processada a partir de Marc Augê $\hat{e}^{9}$ - ao mesmo tempo arena de $\operatorname{conflitos}^{10}$, face e contraface de tensões ideológicas, valorativas, e cenário em que desfilam os sujeitos, muitas vezes carregando laptop e telefone celular. Destacar na locução campo social o termo mediático certamente funciona como indicador de uma circunstância histórica com propriedades singulares, relevantes para se entender o arranjo de forças que marcam contemporaneamente a nossa vida.

Desse modo, uma instituição importante como a escola passa a fazer parte, também ela, dessa ordem no interior da qual os meios de comunicação ganham, para lembrar Jesús Martín Barbero, dimensão estratégica. No momento, não se trata de retomar o debate acerca das mudanças na esfera pública/espaço público, como vinculadas aos novos mecanismos de produzir, circular e receber a comunicação, mas reconhecer o fato segundo o qual a produção do discurso educativo formal, com os seus agentes, ritos, procedimentos, não consegue mais ser entendida ou operada fora da ambiência ampla desse campo social mediático.

Procuramos elaborar subcategorias como campo semântico comum ou campo de interesses comuns, reconhecimento e realização de expectativas sociais, dispersão mediática - referências que deverão acompanhar os desdobramentos futuros desta pesquisa -, para melhor situar os problemas profissionais que acompanham os jovens docentes. Ou seja, enfatizamos a perspectiva segundo a qual o universo simbólico, representativo, que circula pela esfera pública, tem, hoje, a presença mais ou menos desejável do rádio, do jornal, da televisão, da internet, sendo compreensível que existam indicadores de valor e contravalor aproximando os alunos e seus professores que aderiram ao magistério há pouco tempo. A tradução mais evidente desse âmbito semântico ou de interesses comuns pode ser encontrada tanto nos itens afeitos a equipamentos (computadores, por exemplo) como aos próprios produtos mediáticos (manifestados, propriamente, em linguagens como filmes, telenovelas, noticiários etc.).

O problema fundamental, entretanto, é que a constatação da existência da área de proximidade entre jovens docentes e discentes não se esclarece, apenas, na compreensão dos liames arranjados no interior do campo social mediático, tampouco na promoção de um investimento que reoriente o andamento educativo formal, colocando-o ante uma realidade sobre a qual podemos dispensar risos ou lágrimas, mas nunca ignorá-la. É necessário, sobretudo, que o sistema 
Linguagens da comunicação e desafios educacionais • Adilson Citelli

escolar incorpore, fortemente, a ideia de que existe uma permanente luta pela construção das hegemonias discursivas ${ }^{11}$. Se os media prosseguem tão célere e tranquilamente ampliando a sua força constituidora dos espaços públicos, é urgente que a educação formal aumente o som de sua orquestra, caso deseje continuar levando público às salas de concerto.

\section{REFERÊNCIAS BIBLIOGRÁFICAS}

AUGÊ, MARC. Não lugares: introdução a uma antropologia da modernidade. Lisboa: Bertrand Editora, 1994.

BAKHTIN, Mikhail M.; VOLOSHINOV, Valentin N. Marxismo e filosofia da linguagem: problemas fundamentais do método sociológico nas ciências da linguagem. São Paulo: Hucitec, 1989.

CANCLINI, Néstor Garcia. A cultura política entre o midiático e o digital. Revista Matrizes, São Paulo: ECA/USP, n. 2, 2008.

Culturas híbridas: estratégias para entrar e sair da modernidade. São Paulo: Edusp, 1997.

CASTELLS, Manuel. O poder da identidade. Rio de Janeiro: Paz e Terra, 1999.

CITELLI, Adilson. Palavras, meios de comunicação e educação. São Paulo: Cortez, 2006.

(Org.). Outras linguagens na escola: publicidade, cinema e TV, rádio, jogos, informática. 4. ed. São Paulo: Cortez, 2004.

2000.

Comunicação e educação: a linguagem em movimento. São Paulo: Senac,

GAËTAN, Tremblay; MATTELARD, Armand; MIÈGE, Bernard (Org.). 2001 bogues, globalisme et pluralisme. Communication, démocratie et globalization [2001 bugs, globalismo e pluralismo. Comunicação, democracia e pluralismo]. Quebec: Université de Laval, 2003.

GIDDENS, Anthony. Modernidade e identidade. Rio de Janeiro: Zahar, 2002.

GÓMEZ, Guillermo Orozco. A televisão e as crianças. Comunicação \& Educação, São Paulo: CCA-ECA-USP/Moderna, n. 7, 1996.

HABERMAS, Jürgen. Mudança estrutural da esfera pública: investigação quanto a uma categoria da sociedade burguesa. Rio de Janeiro: Paz e Terra, 2003.

HALL, Stuart. Identidades culturais na pós-modernidade. Rio de Janeiro: DP\&A, 1997.

HELLER, Agnés. O quotidiano e a história. Rio de Janeiro: Paz e Terra, 1972.

. A theory of modernity [A teoria da modernidade]. Cambridge: Blackwell Publishers, 1994.
11. A questão do arrefecimento da importância das instituições tradicionais como a escola pode ser acompanhada em CANCLINI, Néstor Garcia. A cultura política entre o midiático e o digital. Revista Matrizes, São Paulo: ECA/USP, n. 2, 2008. 
LÉVY, Pierre. As tecnologias da inteligência: o futuro do pensamento na era da informática. Rio de Janeiro: 34, 1993.

LYOTARD, Jean François. A condição pós-moderna. Rio de Janeiro: José Olympio, 1998.

MARTÍN BARBERO, Jesús. Heredando el futuro: pensar la educación desde la comunicación [Herdando o futuro: pensar a educação a partir da comunicação]. Revista Nómadas, n. 5. Bogotá: Fundación Universidad Central.

MIÉGE, Bernard. La societé conquise par la communication: la communication entre l'industrie et l'espace public [A sociedade dominada pela comunicação: a indústria e o espaço público]. Grenoble: PUG, 1997. Tome 2.

PRENSKY, Marc. Don't bother me, mom. I'm learning! [Não me aborreça, mãe. Estou estudando!]. St. Paul, Minnesota: Paragon House, 2006.

RUBIM, Antônio Albino Canelas (Org.). Idade mídia. Salvador: UFBA, 1995.

SODRÉ, Muniz. Revista Matrizes, São Paulo: ECA/USP, n. 1, 2007.

WITTGENSTEIN, Ludwig. Investigações filosóficas. São Paulo: Abril, 1987. 